\title{
ANTROPONIMOS ARABES CONSERVADOS EN APELLIDOS DEL LEVANTE ESPAÑOL
}

\author{
por \\ Juan Vernet
}

Barcelona

Hellmut Ritter zum 7o. Geburtstage

En un trabajo reciente titulado Antropónimos de etimología árabe en el levante español: ensayo metodológico (En curso de publicación en los Estudios dedicados a Jaime Vicens-Vives) hemos analizado el reparto cuantitativo de los apellidos de etimología árabe en las provincias de Almería, Murcia, Alicante, Baleares, Valencia, Castellón, Tarragona, Lérida y Huesca, demostrando que el porcentaje de dichos apellidos va aumentando conforme se avanza hacia el sur y que su pervivencia es mayor en las zonas rurales que en las ciudadanas, fijando que en la actual provincia de Tarragona quedan como mínimo 5 I23 individuos descendientes de los moriscos. En el presente estudio vamos a inventariar algunos a pellidos de etimología árabe.

La fuente utilizada fundamentalmente en este trabajo ha sido el Anuario Telefónico. Año 1960-r961 que a pesar de sus limitaciones constituye un repertorio onomástico suficientemente completo y muy manejable (véase lo que decimos en la introducción del estudio antecitado) que nos ha permitido obtener 802 papeletés de apellidos árabes radicados en las provincias que nos interesan, escogidas teniendo en cuenta la distribución geográfica de los moriscos tal y como la ha establecido $\mathrm{H}$. Lapeyre (Géographie de l'Espagne morisque, Paris, I959. Cf. la reseña de J. Reglá en Saitabi Io/Io60, IoI-I30). Los nombres así seleccionados no implican, en modo alguno, que sus actuales detentadores tengan sangre árabe en las venas. P'ira poder sospechar la ascendencia árabe de cualquier español (englobo bajo esta dominación a todos los individuos que hablan cualquier lengua P'eninsular) sería necesario pero no suficiente - a falta de árbol genealógico bien establecido - que concurrieran en su apellido una o varias de estas circunstancias: a) que procediera de una voz árabe que no hubiera dado origen a ningrin topónimo ni arabismo peninsular $y$, a ser posible, que ya fuera un antropónimo árabe (v.g. Amete); b) que en el caso de ser de origen no árabe (v.g. Anthonet, leerragut, Martínez) cuando menos uno de sus ascendientes hubiese sido 
procesado por la inquisición por mahometizante o tributado al pico en caliclad de "moro". Estos testimonios dados los excesos cometidos por el Santo Oficio son poco convincente (cf. K. Garrad: la inquisición $y$ los moriscos granadinos, I525-1580, MEAH 9 núm. I, I960, 53-74); c) lue el apellido en cuestión sea considerado, tradicionalmente, como propio de algún linaje musulmán (cf. por ejemplo lo que dice J. Caro Baroja: Los moriscos del reino de Granada, Madrid, I957, p. 263).

Conocemos los apellidos aludidos en $b$ gracias a las nóminas (en Cataluña fugajes) realizallas en la Edad Media con motivos fiscales, a figurar en los textos árabes o en los repartimientos. Los principales trabajos sobre el tema son: IF. Cirlera: Imporlancia de las fuentes árabes para conocer el estado del vocabulario en las lengias o dialectos españoles desde el siglo VIII al XII (Madrid, I9Io); i. Coxlera: Apodos o sobrenombres de moros españoles en: "Mélanges Hartwig-Dérenbourg" (19o9). 323-334; A. Martínez Pajares: Estudio sobre los apellidos y nombres de ligar hispanomusulmanes (Madrid, I918. Muy deficiente); F. Mateu: Nómina de los musulinanes de las montañas de Coll de Rates del reino de Valencia en 1409 , en: A1-Andalus 6/1942, 299-335; A. Masiá: Contribución al conocimiento del censo de la población musulmana: los moros residentes en Cataluña seguin los fogajes de I $49 \mathrm{r}$, 1497 y 1515, en: Tanuda 3/1955, 282-290; J. Bosch: Dos nuevos manuscritos y papeles sueltos de moriscos aragoneses, en: Al-Andalus 22/I957. 463-470 (véase la bibliografía citada en dicho artículo). Han dado repertorios bastante extensos de antropónimos utilizados por los musulmanes del valle del Ebro J. Vernet: El valle del Libro como nexo entre Oriente y Occidente, en: BRABLB 23/1950, 249-286 y M. Grau: Contritución al estudio del estado cultural del valle del Ebro en el siglo XI $y$ principios del $X 1 I$, BRABLIB 27/1957-58, 227-272.

A) BEnNàsar (72, citas)

I) Bennàsak: Baleares: 33, Palma; 2, Alcudia; 2, Ca's Concos; I, Campanet; 2, Campos del Puerto; 9, Felanitx; 4, La Puebla; 3, Mahón; I, Montuiri; 2, Muro; I, Pollensa; I, Porreras; I, Puerto Sóller.

2) Bennaser: Baleares: 3 , Palma; I, La Puebla.

3) Bennasser: Baleares: I, Palma.

4) Bennazar: Baleares: 3, Palma.

5) Bernacer: V'alencia: 2, Valencia.

6) Ben-NACER: Valencia: I, Valencia; Alicante: 2, Alcoy.

Etimología: Ibn Nașr (cf. F. Moll: Els llinatges catalans, Palma de Mallorca, 1959, p. 353). También nombre de un predio en la isla de Mallorca (cf. M. Asin: Contribución a la toponimia árabe de España, Matdrid, ${ }^{2}$ I944, p. 93). El Diccionari català-valencià-balear de Alcover y Moll dice s.v. que este linaje se encuentra extendido por los siguientes lugares: Beniatjar, Gandia, Tabernes de Valdigna (Valencia) y Alaró, Alcurdia. Bibisalem, Calvià, Campanet, Campos, Felanitx, Inca, Llubí, Palma etc. (Baleares). El epónimo de esta familia es un musulmán que se sometió a Jaime I en el momento de la conquista (cf. Ch. de Tourtoulon: Jucme I le Conquerant, Montpellier, 1867, II p. 625-626). A pesar de su 
origen árabe algunos de sus miembros fueron procesados por juda1zantes (?!) (cf. Inquisición de Mallorca. Reconciliados y relajados 1488 169I, ed. M. Perdigó, Barcelona, 1946, indices).

Los datos que aporta el Diccionari... de Alcover y Moll, muy interesantes y nutridos, no han sido tomados aquí como base por registrar sólo la localización geográfica de los apellidos, sin aludir a su densidad.

B) NACHER $(65$, citas)

I) Nacher: Castellón: 4, Alcora; 3, Villareal; Valencia: 38, Valencia; I, Adzaneta; 2, Albaida; I, Alcira; 1 , Aldaya; I, Betera; 4, Catarroja; I, Corbera; 2, Cullera; I, I.iria; I, Tabernes de V.; 2 , Algemest.

2) NÁCHEZ: Valencia: I, Valencia.

3) NAcins: Almeria: I, Balerma.

4) Nache: Almería: I, Almería; I, Balerma.

Etimología: Nağğār. Esta etimología parece segura, pues en el libro de Habices de las mezquitas de la ciudad de Granada y sus alquerias (ed. C. Villanueva, Madrid, I96I) indices se encuentran varios personajes de este nombre. Diccionari... s.v. dice que este linaje se encuentra extendịdo por Adzaneta, Culla, Castellón, Vistabella, Valencia, Alfafar, Sollana, Burjassot, Vilallonga, Játiva, Alcoy, Biar, etc.

C) BABILONI (56, citas)

I) Babiloñ: Castellón: 4, Castellón; Valencia: 2, Valencia.

2) Bibiloni: Baleares: 35, Palma; 3, Alaró; 2, Algaida; 7, Binisalem; I, Capdepera; I, Sancellas; Alicante: I, Alicante.

Etimología: Patronímico de Babalyūn, ciuclad egipcia (cf. el artículo de C. H. Becker en EI '2I, I960, 865-866). F. Moll: Els llinatges... registra la primera cita en i 76 . Cabe pues suponer que las personas que recibieron este apelativo tuvieron un origen egipcio, es decir, musulmán. Diccionari s.v. dice que este linaje se encuentra en Tàrrega, Valencia, Castellón, Alcora, Almassora, Borriol, Villarreal etc.

D) Massot (40, citas)

I) Massot: Tarragona: I, Reus; Lérida: I, Almacellas; I, Balaguer; Baleares: 21, Palma; I, Mahón; I, Sancellas.

2) Masor: Tarragona: I, Iilix; 2, Reus; I, Iiraga; Lérida: I, Iérida; I, Miralcamp; I, Tárrega; Huesca: I, Kraga; Valencia: 2, Valencia.

3) Massuti: Baleares: I, Felanitx.

4) Massoti: Valencia: I, Valencia; Murcia: 2, Murcia.

Etimología: Mašūd (cf. I'. Moll: Els llinatges . .p. 353). Como topónimo existe un Benimasot en la provincia de Alicante (cf. Asin: Contri- 
bución... p. 9I). Diccionari... s.v. dice que este linaje se encuentra en Cebrà, Flaçì, Gerona, Mont-Ras, Barcelona, Vilafranca del Panades, Reus, Flix, Lamacelles, Algerri, Almenar, Alicante, Mallorca etc.

E) Calar $(27$, citas)

I) Calari: Lérida: I, Mollerusa.

2) Calaf: Lérida: I, Léricla; I, Balaguer; I, Tárrega; Tarragona: I, Arbós; I, Reus.

3) Calafell: Baleares: 9, Palma; I, Ciudadela; I, Esporlas; I, Inca.

4) Calafat: Baleares: 7, Palma; I, Capdepera; I, Santa María.

Etimología: Xalaf (cf. F. Moll: Els llinatges... p. i8r). Para la forma Calafat cf. J. M. Millás: Desinencias adjetivales romances en la onomástica de nuestros judios (en ,Estudios dedicados a Menéndez Pidal", I (I950), I25-I33) y F. Moll, loc. cit. p. 294. Como topónimo se conserva en la provincia de Lérida. Diccionari... s.v. dice que este linaje se encuentra en Albinyana, Anglesola, Barbarà, Barcelona, Brafim, Castellví de la Marca, Masllorens, Puigpelat, Tarragona, Valencia, Valls etc...

F) FAYOS (25, citas)

Carece de variantes. Valencia: 2, Alberique; I, Alcudia; 2, Algemesí; I, Camals; 2, Carcagente; 2, Favareta; I, Gandía; I, Játiva; 5, Iugar nuevo de San Jerbnimo; I, Macastre; 2, Manuel; 2, Rotova; 2, Sueca; I, Villanueva de $\mathrm{C}$.

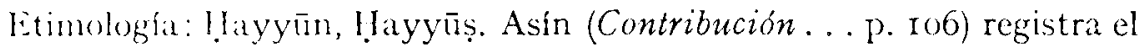
topónimo fayón en Zaragoza. Para la forma. Fayós véase E. Carcía crómez: Hipocoristicos árabes y patronimicos hispanos (Arabical I, I954, 12()-I 35) y li. Moll: Els llinatges ... p. 354 s.v. Mainús.

G) Benimela (25, citas)

I) Brenmeli: Valencia: 5, Valencia; I; Oliva;, Alicante: I, Alicante; 2, Callosa de Segura; I, Cañada; I, Pego.

2) Binimelis: Baleares: 8, Palma; 2, Porto Cristo.

3) Vilimilis: Lírida: I, Villanueva de la Barca.

4) Benimell: Valencia: I, Valencia.

5) Benimeri: l'alencia: I, Oliva.

b) Benimelir: Alicante: I, Alicante.

Etimología: Bani Malị̣ ó Bani Mālik. Esta última la sostiene el Dicciunari s.v. que dice, ,aquesta etimologia és confirmada per la forma antiga que apareix a un document de l'any $\mathrm{r} 560 \mathrm{com}$ a nom del poble que "vuy se diu Benineli". Sin embargo, Asin (Contribución ... p. gr) y en pos de este F. Mull (Vils llinatges... p. 353) recogen la primera. 
H) Gasulla (24, citas)

I) Gasulla: Tarragona: I, Tarragona; I, Reus; I, Tortosa; Castellón: 3 , Morella; Valencia: 4, Valencia.

2) Gasull: Tarragona: 2, Tarragona; I, Almoster; I, Montblanch; I, Reus; I, Fulleda; Valencia: 5, Valencia; 3, Torrente.

Etimología: de Gazūla ó Qazūla, nombre de una tribu presahariana citada por Idrisi (Description de l'A frique et de l'Espagne, ed. Dozy-De Goeje, p. 70). El mismo nombre forma parte del topónimo Alcalá de los Gazules (cf. Asín: Contribución...p. po). F. Moll: Els llinatges... p. Iog lo emparenta, a nuestro entender indebidamente, con el antropónimo peninsular Garcia. Diccionari s.v. señala la primera cita en un documento de I277 y dice que este linaje se encuentra en Caravelles, Castelló d'Ampuries, Pals, Parlabà, Rupià, Sarrià, Calaf, La (Garriga, Barcelona, Igualada, Mataró, Cornellí, Albi, Albiol, Almoster, Castellvell, Tarragona, Montblanc, L'Ametlla, Villarreal, Valencia, Torrent, Ienia etc. La forma Gasulla predomina en cambio, según la misma fuente en Hospitalet, Benicarló, St. Mateu etc.

I) Margaler (22, citas)

Carece de variantes. Lérida: I, Lérida; Tarragona: I, Tarragona; 4, Amposta; I, Ascó; I, Benifallet; I, Lat Aldeat; I, La linguera; I, Mora la Nueva; I, Perelló; 7 Reus; 1, Tivisar; I, Tortosá Buleares: I, Palma. Etimología: Marğ Xialaf (cf. li. Moll: Els llinatges ... p. I(g4). Existe como topónimo en la provincia de Tarragona. Diccionari s.v. dice que se encuentra extendide por Tarragona, Valls, Cambrils, Benifallet, lialset, Marça, Tivissa, Ginestar, Mora d'libre etc.

J) JODAR (I8, citas)

Carece de variantes. Castellón: I, Segorbe; Valencia: I, Catarroja; Murcia: I, Murcia; 3, Cartagena; II, Lorca; I, Los Barreros.

Etimología: Gawdar. lixiste como topónimo en la provincia de Jaén (cf. Asin: Contribución... p. I 15 sobre la forma Sawdar =-- Jódar). La historia de este patronímico en el mundo andalusí puede verse estozarla en E. Terés: Linajes árabes en al-Andalus segrin la $\widehat{Y}$ amhara de Ibn Hazm Al-Andalus 22, 1957, 104 .

K) Maimó (15, citas)

I) Maimó: Tarragona: I, Arbós; r, Bañeras; I, La Alleá; Buleares. 6, Palma; I, Ca's Concos.

2) Maymó: Lérida: 3, Tarrega; Valencia: I, Valencia.

3) Maymón: Valencia: 1, Valencia. 
Etimología: Maymūn (cf. F. Moll: Els llinatges ... p. 354). Este antropónimo abundaba muchísimo en Mallorca durante la dominación musulmana, pues Ramón Lull lo utiliza siempre que quiere dar nombre a un musulmán cualquiera y equivale a nuestro fulano actual o a los Juan y Pedro que utilizamos en los ejemplos gramaticales. Diccionari s.v.: Linaje extendido por San Feliu de Guixols, Barcelona, Montornés, Lliça de Munt, Mataró, Mollet, Molins de Rey, Argentona, Tarragona, Reus, Garcia, Arboç, Altafulla Ginestar, Tortosa, Aranyò, Useres, Alicante, Mallorca etc.

L) Benejam (13, citas)

Carece de variantes. Baleares: 9, Ciudadela; 3, Mahón; Valencia: I, Valencia.

Etimología: Bani 'Ağam. Para otras etimologías puede verse F. Moll: Els llinatges ... p. 308 y Asin: Contribución ... p. 86 al explicar el topónimo Benejama.

M) Vinaixa (II, citas)

I) VINAIXA: Tarragona: I, Benisanet; 2, Mora la Vieja; I, Reus;Castellón:

2, Nules; I, Portell de Morella.

2) Vinaja: Castellón: I, Vinaroz; Valencia: I, Valencia.

Etimología: Ibn 'A'iša (cf. F. Moll: Els llinatges... p. 355). Existe como topónimo en la provincia de Lérida (cf. Asín: Contribución... p. I 42). Un clan omeya tuvo este nombre (cf. Terés: Linajes árabes... p. 83 ).

N) Aventin (ro, citas)

Carece de variantes. Huesca: 4, Graus; I, Monzón. Lérida: 5, Lérida. Etimologia: Ibn Hamdin. Las formas intermedias están documentadas: Auenhamdin (II44), Abeandin (II46). Cf. J. M. Lacarra: Documentos para el estudio de la reconquista y repoblación del valle del Ebro, Eimcaz 3/1949, 612, 617.

O) Ambros (4, citas)

Carece de variantes. Huesca: I, Alcampel; Baleares: r, Palma; Valencia : 2, Valencia.

Etimología: 'Amrūs. Asín: Contribución... p. 75 lo cita como topónimo en las provincias de Cáceres, Granada y Madrid. F. Moll: Els llinatges ... p. I2r lo deriva del latin Ambrosius.

P) Amate (4, citas)

I) Amate: Almería: I, Gádor; I, Huercal-Overa.

2) Ametis: Almeria: 2, Benahadux. 
Etimología: Aḥmad. Asín (Contribución... p. 75) cita un topónimo Amete como despoblado de la provincia de Almería.

Q) Bujaldon (3, citas)

r) Bujaldón: Almeria: r, Los Gallardos; r, Purchena.

2) Bujaldán: Almeria: I, Purchena.

Etimología: Abū Xaldūn. La variante Bujaldán parece ser una errata de imprenta del Anuario. 